\title{
Registros geológicos da era glacial neopaleozoica no estado do Paraná e demais regiões do sul do Brasil: introdução ao volume temático
}

\author{
FERNANDO FARIAS VESELY ${ }^{1}$ \\ ${ }^{1}$ Departamento Geologia - UFPR, Brasil, https://orcid.org/0000-0002-6741-8589, vesely@ufpr.br
}

A era glacial neopaleozoica ou do Paleozoico tardio (late Paleozoic ice age - LPIA) foi marcada por glaciações em altas e médias latitudes do Gondwana, por grandes variações do nível dos mares e pelos níveis mais baixos de gás carbônico atmosférico registrados em todo o Fanerozoico (Fielding et al., 2008; Isbell et al., 2012; Montañez \& Poulsen, 2013). Esse período contém ainda o único registro da transição completa de condições glaciais para condições pós-glaciais numa Terra colonizada por vegetação terrestre (Gastaldo et al., 1996).

A concepção recente de que a LPIA seria um análogo antigo para se compreender mudanças climáticas modernas (Gastaldo et al., 1996; Montañez \& Poulsen, 2013) despertou na comunidade científica o interesse por refinar seu registro estratigráfico e aperfeiçoar os modelos paleoclimáticos. Isso trouxe a necessidade de reexaminar os marcadores (proxies) presentes nas rochas permocarboníferas (Isbell et al., 2021), tanto nas regiões diretamente afetadas por glaciação (marcadores proximais), quanto nas bacias sedimentares paleotropicais e paleoequatoriais afetadas indiretamente pelos ciclos glaciais (marcadores distais), causando uma verdadeira "revolução geocientífica do neopaleozoico".

Essa revolução tem seguido três vertentes principais. A primeira se presta a reconstruir os antigos ambientes da $L P I A$ mediante o reexame dos depósitos glaciais e pós-glaciais (vertente sedimentológica), ao passo que a segunda tem como objetivo principal posicionar os eventos geológicos no tempo com a maior precisão possível (vertente geocronológica). Há ainda uma terceira vertente, a paleoclimática, que utiliza marcadores isotópicos e/ou geoquímicos contidos nas rochas permocarboníferas para investigar o intercâmbio entre a paleoatmosfera, a paleocriosfera, a paleobioesfera e as mudanças climáticas.

A Bacia do Paraná contém um dos registros geológicos mais volumosos de glaciação neopaleozoica (Franca \& Potter, 1988) e por isso tem sido um importante objeto de estudo dos marcadores proximais da $L P I A$. Como consequência, inúmeros trabalhos foram feitos nos últimos anos, em grande parte publicados em revistas internacionais especializadas. A disseminação desse conhecimento é efetiva no meio científico envolvido nas pesquisas, mas muitas vezes é ineficaz na comunidade mais geral.

Nesse sentido, este volume especial tem como objetivo divulgar, em língua portuguesa, alguns elementos geológicos da LPIA na Bacia do Paraná, em especial no estado do Paraná e sul do Brasil, com foco na vertente sedimentológica. O volume foi elaborado mediante a releitura de resultados recentemente obtidos por pesquisadores da Universidade Federal do Paraná que tem participado ativamente da revolução geocientífica do Neopaleozoico. A ideia de publicar esse volume foi ainda motivada pela produção do novo mapa geológico do Paraná (CPRM, 2021) em que, pela primeira vez, o pacote sedimentar correspondente à LPIA (Grupo Itararé) aparece dividido em unidades litoestratigráficas.

No primeiro artigo do volume, Vesely, Delgado, Spisila e Brumatti tratam justamente da divisão do Grupo Itararé em formações, membros e unidades informais tal como exposto no novo mapa geológico do Paraná, no intuito de estabelecer um arcabouço litoestratigráfico de base para os outros artigos, que abordam temas mais específicos. Esse trabalho consiste, portanto, numa nota explicativa da litoestratigrafia do Grupo Itararé no estado do Paraná.

A parte basal do Grupo Itararé, assim como o seu substrato cristalino ou sedimentar é a que apresenta as evidências mais claras de glaciação. É bem documentado que nas bordas leste (São Paulo, Paraná e Santa Catarina) e sul (Rio Grande do Sul) da Bacia do Paraná geleiras avançaram de sul-sudeste para norte-noroeste. Esse sentido geral de fluxo é registrado por geoformas erosivas que contêm indicadores cinemáticos tais como estrias, sulcos e megalineações. Contudo, Rosa, Vesely, Isbell e Fedorchuk destacam que nos três estados do sul do Brasil existem diferenças quanto ao tipo de substrato sobre o qual o gelo se deslocou, assim como quanto à própria geometria das geleiras, o que indica variabilidade significativa do estilo de glaciação ao longo da bacia.

Depósitos glaciais podem ser macroscopicamente maciços e homogêneos, dificultando a interpretação dos seus processos formadores. Nesses casos, o exame de microtexturas e microestruturas em seções delgadas pode elucidar os processos deposicionais e deformacionais experimentados por essas rochas, auxiliando assim na interpretação paleoambiental. Na geologia sedimentar, essa abordagem tem sido denominada de "micromorfologia". O trabalho de Garcia, Trzaskos, Vesely, Rosa e Isbell é o primeiro estudo sistemático de micromorfologia em rochas glaciais do Grupo Itararé e um dos poucos que usa esse método em depósitos glaciais mais antigos do que o Quaternário. 
Um tema crítico para compreender as causas e consequências da mudança climática do Neopaleozoico é o contexto paleoambiental em que teria ocorrido o final da glaciação durante a LPIA. Na Bacia do Paraná, o último (mais jovem) registro de glaciação situa-se na Formação Taciba, a unidade litoestratigráfica superior do Grupo Itararé. No intuito de detalhar esse importante intervalo estratigráfico, Mottin e Vesely descrevem a Formação Taciba na região de Ibaiti, nordeste do Paraná, um dos lugares onde os diamictitos glaciais mais jovens da bacia estão bem representados em afloramento. A partir duma análise estratigráfica detalhada e de levantamento de indicadores de transporte sedimentar, esses autores determinam que há pelo menos dois eventos de glaciação registrados na Formação Taciba e que o sentido das paleocorrentes é distinto daquele observado em intervalos estratigráficos sotopostos.

Diamictitos são rochas mal selecionadas, homogêneas ou heterogêneas, tipicamente constituídas por clastos de diversos tamanhos, formas e composições dispersos numa matriz lamosa ou areno-lamosa. Embora existam inúmeras evidências de influência glacial nos diamictitos do Grupo Itararé, sabe-se que a grande maioria desses depósitos não foi formada em contato direto com as geleiras, ou seja, não são diamictitos verdadeiramente glaciogênicos. Ao contrário, são fácies oriundas de escorregamentos subaquáticos, muitas vezes desvinculadas dos processos glaciais. Essa constatação é muito importante do ponto de vista paleoclimático, pois indica que a presença de diamictitos por si só não pode ser vista como marcador de glaciação. Uma das formas de compreender como esses movimentos de massa subaquáticos evoluem e produzem diamictitos é através do exame da deformação penecontemporânea registrada nessas rochas. Rodrigues, Trzaskos, Vesely e Mottin ilustram a grande variedade de estruturas deformacionais presente nesses depósitos.

Além dos diamictitos, ritmitos são fácies típicas do registro proximal da LPIA. Nos estudos pioneiros do Permocarbonífero da Bacia do Paraná, esses depósitos eram interpretados como varvitos, ou seja, sedimentos lacustres caracterizados por sazonalidade da sedimentação. Um dos primeiros trabalhos que propôs uma interpretação alternativa foi o de Salamuni et al. (1966), que consideraram os ritmitos como turbiditos ao invés de varvitos. Esse foi, inclusive, o primeiro relato sobre turbiditos nas bacias sedimentares brasileiras. Hoje sabe-se que turbiditos são amplamente distribuídos pelo registro do Grupo Itararé. Assim, no último artigo deste volume, Vesely, Kraft, Mattos, Schemiko, Berton, Monteiro e Yamassaki revisitam turbiditos do Grupo Itararé e discutem sua gênese no contexto da LPIA.

A recente revolução geocientífica do Neopaleozoico inaugurou nova fase na pesquisa sobre a LPIA na Bacia do Paraná, em especial no sul do Brasil. O conteúdo deste volume temático é uma pequena amostra de alguns resultados recentemente alcançados. Na esteira desse processo, grupos de pesquisa se consolidaram e colaborações internacionais importantes foram estabelecidas, contribuindo para o avanço das geociências e para a formação de novos geocientistas hoje atuando na pesquisa e no ensino em universidades dentro e fora do país.

\section{Agradecimentos}

Os artigos deste volume derivam de pesquisas financiadas por diferentes agências ao longo dos últimos anos. Agradeço em especial ao $\mathrm{CNPq}$ e à Petrobras pelo contínuo apoio financeiro e à CAPES por prover bolsas de mestrado e doutorado a vários dos autores envolvidos. Agradeço ainda ao editor associado do Boletim Paranaense de Geociências, Carlos Conforti Ferreira Guedes, pelo gerenciamento do volume, à Seção de Apoio às Publicações Científicas Periódicas da UFPR pela diagramação e aos 12 especialistas de diferentes instituições que voluntariamente se dispuseram a revisar os manuscritos e sugerir modificações que em muito melhoraram a qualidade desta publicação.

\section{Referências}

CPRM - Serviço Geológico do Brasil. 2021. Mapa Geológico e de Recursos Minerais do Estado do Paraná. Programa Geologia, Mineração e Transformação Mineral, Curitiba: CPRM, 2021, 1 mapa colorido, 235 x $90 \mathrm{~cm}$. Escala 1:600.000.

FRANCA, A. B., \& POTTER, P. E. 1988. Estratigrafia, ambiente deposicional e análise de reservatório do Grupo Itararé (Permocarbonífero), Bacia do Paraná (Parte 1). Boletim de Geociências - Petrobras, 2(4), 147-191.

FIELDING, C.R., FRANK, T.D., ISBELL J.L. 2008. The late Paleozoic ice age - A review of current understanding and synthesis of global climate patterns. In: C.R. Fielding, T.D. Frank, J.L. Isbell (Eds.), Resolving the Late Paleozoic Ice Age in Time and Space, Geological Society of America Special Publication, Boulder, CO, pp. 343-354

GASTALDO, R. A., DIMICHELE, W., PFEFFERKORN, H. 1996. Out of the icehouse into the greenhouse: a late Paleozoic analogue for modern global vegetational change. GSA Today 6, 1-7.
ISBELL, J. L., HENRY, L. C., GULBRANSON, E. L., LIMARINO, C. O., FRAISER, M. L., KOCH, Z. J., CICCIOLI, P. L., \& DINEEN, A. A. 2012. Glacial paradoxes during the late Paleozoic ice age: Evaluating the equilibrium line altitude as a control on glaciation. Gondwana Research, 22(1), 1-19.

ISBELL, J.L, VESELY,F.F., ROSA, E.L.M., PAULS, K.N., Fedorchuk, N.D., Ives, L.R.W., Mcnall, N.B., LITWIN, S.A., BORUCKI, M.K., MALONE, J.E., KUSICK, A.R. 2021. Evaluation of physical and chemical proxies used to interpret past glaciations with a focus on the late Paleozoic Ice age, Earth-Science Reviews (in press).

MONTAÑEZ, I.P., POULSEN, C.J. 2013. The late Paleozoic ice age: an evolving paradigm. Annu. Rev. Earth Planet. Sci., 41 (24) (2013), pp. 1-28.

SALAMUNI, R.; MARQUES FILHO, P.L.; SOBANSKI, A.C. 1966. Considerações sobre turbiditos da Formação Itararé (Carbonífero Superior), Rio Negro-PR e Mafra-SC. Boletim da Sociedade Brasileira de Geologia, 15: 1-19. 